\title{
An Analytical Study of the Scientific Research in the Field of Sports Shows in the Period from 1980 to 2010.
}

\section{Mohamed Mersal Hamad Arbab}

Professor of exercise in curriculum \& Teaching Methods of sports Education Dept., Faculty of sports Education Mansoura University. Egypt.

\section{Hazem Ahmed Mohamed El Sayed}

Assistant Lecturer in curriculum \& Teaching Methods of sports Education Dept., Faculty of sports Education Damietta University. Egypt.

\begin{abstract}
The present study aims to analyze scientific research in sports shows from1980to2010 for identifying the number, type,temporal distributionof the research and the most commonly scientific research used,the relative variation in the adopted research processes which pertinent to the used research design and sample (Selection method of sample, Participants number, Participants age, Sex and the geographical distribution of sample )and Identify the variables that associated with the sports shows, which gained attention of researchers and which have not been

The researchers used the descriptive method of analytical survey through conducting a comprehensive survey of all scientific researches in the field of sports shows.after that the data of research study has been collected in a form which statistically processed using the percentage. Conclusions:The number of researches was Master (14), PhDs (4), published scientific production (43), the number of such researches gradually increase with the time, the experimental method was the most frequently used instead of historical method. The samples were randomly collected and their numbersrangedfrom20-500 people, mainly males. Their stages "19-22 years" and the field of coordination, movement, physical abilities which were the most interest among researchers.
\end{abstract}

\section{Introduction}

$\mathrm{T}$ he evolution considers one of the most important goals sought by the man and the fulfillment of his desire to Highness to all creatures, and to prove itself, and a desire to welfare, so the developed countries are interested in resolving their problems in scientific methods that will work to bring about development and progress desired in all fields.

In the modern era, The sport has progressed tremendous progress to be pursued scientific approach codified in addressing issues, and even became a scientific research in the field of physical education and sports occupies a prominent place in the colleges of physical education and contribute to the evolution of thinking Sports Educational sophisticated deep and this explains the increasing numbers of scientific research and studies provided by the colleges Physical Education in the recent period.

These researches consider a mainly basiswhich development and progression physical education sports based on whether in the field of Applied by reaching results contribute to the development of different 
areas of Physical Education or in the theoretical field where research is of references important can refer to it and which is a guide for researchers.

Recently the countries identified to the importance sports shows where both Zahran, Lilly Abdel Aziz (1997) and Faraj, Inayat Mohammed and El batal, Faten Mohamed (2004), and Khattab, Attiyat Mohamed et al (2006)agree that sports shows are faced to measure the progress of peoples sporty therefore given states advanced particular interest to them, Sports shows are mirror which reflected the image of the society and have an effective impact in terms of nationalism as it works to show the progress of civilization, sporty culture, and model for social and political systems healthy in the community, sports shows have important and active role in the creation of a good citizen, and comprehensive education integrated and upgrading health of the individual and the development of work and increase production and access to high athletic levels high through the use of collective exercise(12: 119) (5: 277) (8:344)

Therefore, we find that the sports shows like other sports activities, using of the scientific method in solving problems, and is reflected in the research and reference studies which dealt sports shows, which increased significantly in the recent period, and it would work on the progress and development sports shows and upgrading concept than just gathering for athletes and meetings for youth only, to a scientific approach addressed by researchers in various parts of the Arab world in research, development, and creation.

One the most important scientific steps to upgrade any aspect of society, is to stand on the outcome of what has been accomplished, and try to analyze it, and evaluation to enable researchers to start from the reality known in the research and investigation to develop and progress this aspect with minimal effort and little time as possible.

In spite of the multiplicity of reference studies in the field of sports shows, the researchers found no any function Informatics refers to the reality of this research and nature glance comprehensive comparative analysis, which highlighted a problem for us effect research work qualitative researchers without having to communicate scientific with previous research in a holistic manner, comparative and so the researcher can start from where the others have ended.

So the researchers surveyed the published scientific production research and Masters and $\mathrm{PhDs}$ licensed in the period from 1980 until 2010 in the field of sports shows, and analysis them.

So the importance of current research is to provide a database containing all the details of researches in sports shows, comprehensive manner analytical and comparative, it is an attempt to map the monitor the reality of scientific research in the field of sports shows to help researchers identify the strengths and promotion, and identify weaknesses and try to treat, in order to improve the methodology of scientific research in the field of sports shows.

\section{The Objective of this research}

This study aims to analyze researches conducted in the field of sports shows in the period from (1980 to 2010) in Egyptian universities through,

1. Identify a (research type) of the studies undertaken during this period.

2. Identify a (temporal distribution) of these studies. 
3. Identify the relative variation in the adopted research processes which pertinent to the used research design and sample (Selection method of sample, Participants number, Participants age, Sex and the geographical distribution of sample )

4. Find out to what extent these studies addressed appropriate tools in sports shows.

5. Identify the variables that associated with the sports shows, which gained attention of researchers and which have not been

\section{Reference studies}

Study Elbahar, Yasmin Hassan and Abdel Halim, Mona Mahmoud. (1991) (2)."An analytical study for the theses and dissertations in the field of exercises In the period from 1972 to1990" The study aimed to analyze the master's and doctoral degrees in the field of exercise from 1972 to 1990 in order to identify more fields that researchers during that period, as well as fields that have not received their interest, and use the researchers survey method was statistical treatment of the data using the percentage and was the most important results in the lack of relative balance between areas of research associated of exercise occupied the field of training and physiological ranked first in terms of the attention of researchers followed the field of biomechanics, followed by the field strength. The experimental method is more scientific research methods used in this research.

\section{Search procedures}

Research Methodology: Researchers used the descriptive method, by analytical survey style.
Data collection tools: Researchers designed a special form to collect data.

\section{Data collection:}

The researchers conducted a survey of all scientific research (published scientific production research, theses and doctoral dissertations that are discussed) in the period from 1980 to 2010, in the sports shows at existing libraries of faculties of sports education in Egyptian universities, was the final number of research addressed by the study (61) in search they sport shows one of the variables, and the researchers collected data on the type of study, date of publication or discussion, procedures of sample selection (number type and method of selection and the age group and geographical dimension to them), type method that was used and whether it sports shows independent variable or dependent variable, And other variables of theoretical and practical sciences addressed by under study research, and linked between them and sports shows, and to identify the more these variables addressed by researchers and other variables that overlooked by Researchers.

\section{Statistical processors:}

Data were treated statistically using the percentage.

\section{discussion and interpretation of the results}

Table (1)

Types of under study Researches

\begin{tabular}{|c|c|c|}
\hline Research Type & $\begin{array}{c}\text { Number of } \\
\text { Researches }\end{array}$ & Percentage \\
\hline Master & 14 & $22.95 \%$ \\
\hline Doctorate & 4 & $6.56 \%$ \\
\hline $\begin{array}{c}\text { Scientific } \\
\text { production }\end{array}$ & 43 & $70.49 \%$ \\
\hline Total & 61 & $100.00 \%$ \\
\hline
\end{tabular}




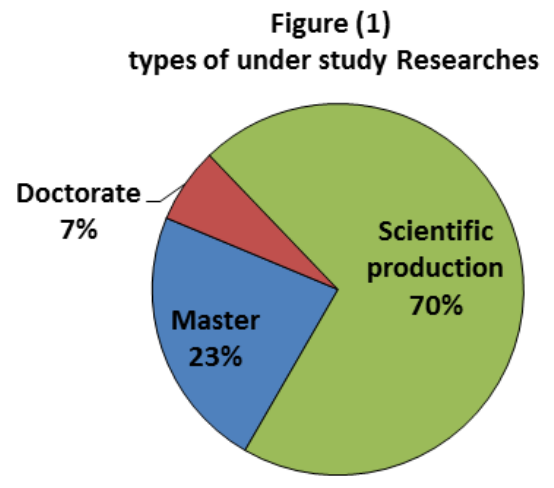

Table (1) showed that the number of research on sports shows in the period from 1980 to 2010 of reached 61 searches in its entirety, It is divided in terms of type, according to the degrees of scientific to scientific researches produced in Scientific Journals Egyptian and ranked first number reached 43 by $70.49 \%$, thesis to obtain master's degree and ranked second reached 14 by $22.95 \%$, while it is ranked numerically recent thesis to obtain a $\mathrm{PhD}$ degree in sports education reached 4 by $6.56 \%$. As shown in the figure (1) the relative differences between the three types research in terms of the number and percentage.

The researchers believe that the Percentage differences in type at under study researches is described in the figure (1) may be due to the characteristics of the procedural system of higher studies at sports education faculties and Promotion system where required to get a master's or doctoral degree leave thesis for each degree, while obliges promotion systems of professors and associate professors published four scientific research at least for the researcher, which explains the numerical increase of research output scientific for Masters and PhDs, and researchers believe that the relative difference between the number of Masters and the number of doctoral thesis which described in figure (1) may be due to the nature of the numerical increase for students enrolled in a master's degree on the number of students enrolled in doctoral degree and this is consistent with that, according to last count by the Central Agency for Public Mobilization and Statistics on the number of recipients Masters in Humanities from 1990 $\mathrm{m}$ to $2010 \mathrm{~m}$ reached 29,072 students by $66 \%$, while the number of recipients Ph.D. in the same area and the same period amounted to 15167 students by $34 \%$. (13)

Table (2)

temporal distribution of under study Researches

\begin{tabular}{|c|c|c|}
\hline Time periods & $\begin{array}{c}\text { Number of } \\
\text { researches }\end{array}$ & Percentage \\
\hline 1980 to 1985 & 4 & $6.56 \%$ \\
\hline 1986 to 1990 & 5 & $8.20 \%$ \\
\hline 1991 to 1995 & 8 & $13.11 \%$ \\
\hline 1996 to 2000 & 9 & $14.75 \%$ \\
\hline 2001 to 2005 & 15 & $24.59 \%$ \\
\hline 2005 to 2010 & 20 & $32.79 \%$ \\
\hline Total & 61 & $100.00 \%$ \\
\hline
\end{tabular}

Figure (2)

temporal distribution of under study Researches

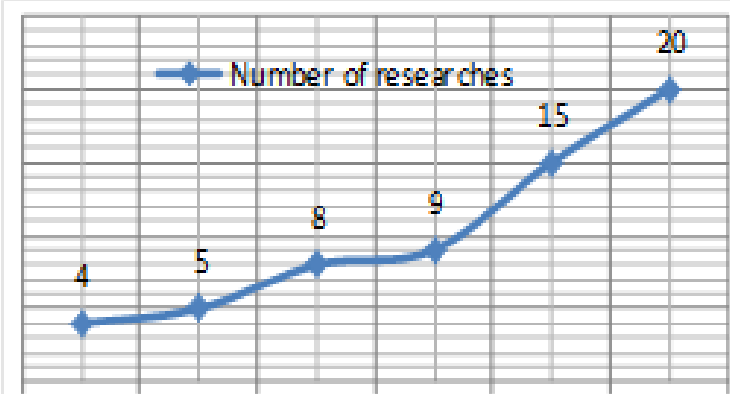

1980 to 1986 to 1991 to 1996 to 2001 to 2005 to $\begin{array}{llllll}1985 & 1990 & 1995 & 2000 & 2005 & 2010\end{array}$

Table (2) showed that there is variation in the temporal distribution of the under study researches on the time periods, where department researchers total time under study (30 years) to 6 equally periods, show that the period from 1980 to 1985 was least interested in the field of scientific research in sports shows, where the number of research 4 by $6.56 \%$, it also found that the period from 2006 to 2010 was most interested in the field 
of scientific research in sports shows where the number of research 20 by $32.79 \%$.

Figure (2) showed that the time distribution curve for under study researches is a curve upward, which refers to the existence of a direct correlation is positive correlation between the number of research and the rate of passage of time, and so the obvious difference in the temporal distribution of the number of research in table (2), showing in the figure (2) as a relative increase output of positive relationship between the number of research and progress in time.

The researchers believe that increase relative in the under study researches may be due to increased awareness of the importance sports show, who is following the history development of sports shows finds that there is considerable interest to foster the culture sports shows, preparation and implementation and evaluation recently, This is consistent with the reported Khattab, Attiyat Mohamed et al (2006) that recently identified the countries to the great importance of the sports shows not only at the local level but at the global political, economic and intellectually, and interested most countries, including Egypt sports shows and consider the task of nationalism should every citizen and his compatriot contribute, and Moneisi, Iman Mohammed (1995) adds that sports shows is one of the finest athletic levels undisputed, therefore, developed countries in sports focused on sports shows, every state has its own character, and its concept in the style of sports shows. (8: 344) (9: 1), so researchers believe that increased attention in sports shows recently in local and global communities, have reflected positively on the growing interest in subjecting this area of scientific research, which helped to attract researchers to research and study in sports shows, which may explain the increase relative at the under study researches.

Table (3)

Research Methods used in the under study Researches

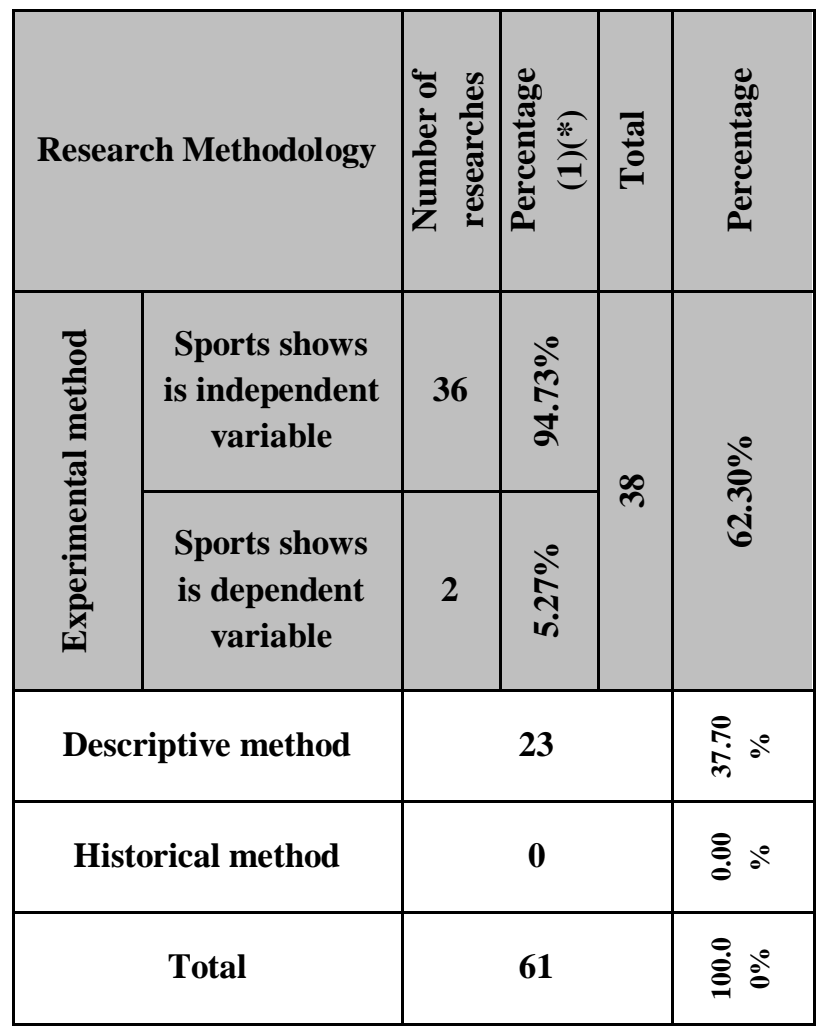

(*)Percentage (1) means Percentage of total number of research which addressed sport shows as an independent variable or dependent variable of the researches used experimental method.

Figure (3)

Research Methods used in the under study Researches

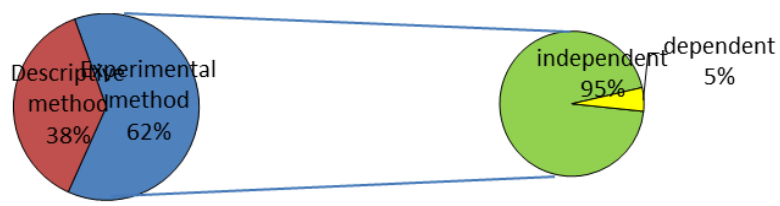

Table (3) and Figure (3) showed that the number of research used in the procedures experimental method was 38 by $62.30 \%$, divided in terms of the independence of the variable sports shows to sports shows is independent variable reached 36 by $94.73 \%$ of the total research which used the 
experimental method, and sports shows is dependent variable reached two researches by $5.27 \%$ of the total research which used the experimental method, while the number of research that used descriptive method in procedures 23 by $37.70 \%$ of the total under study research, and either the historical method is not used in the under study researches.

The researchers believe that the trend for experimental method is greater than Descriptive method may be due to the desire of researchers in creating experimental positions with control scientific in order to reach maximum accuracy in the results, The experimental method is closer research methodologies to solve problems by scientific way.Saber, Fatima Awad and Khafajah, Mervat Ali. (2002) refer to that the experimental method is the approach that is the parameters of the scientific method is also is the research methodology only one who can real test of the hypotheses relations resulting from the seizure of scientific arbitrator which allows the researcher to draw conclusions more accurate(10: 57), and consistent this with the results of study of Elbahar, Yasmin Hassan and Abdel Halim, Mona Mahmoud. (1991).(2),the researchers also did not use the historical method, may be due to the misconception among researchers that historical research is not valuable and without important because the nature of historical research may not reach to the laws fixed or scientific theories specific or certain generalizations, and recalls in this regard Saber, Fatima Awad and Khafajah, Mervat Ali. (2002)that failure to reach historical research to scientific laws or theories never reduces the value and the importance of historic research and the fact that it was research analytic rely on Critique the past to predict the future and take advantage of the present to interpret the past (10: 44).

Table (4)

Selection methods of samples

\begin{tabular}{|c|c|c|}
\hline Selection methods & $\begin{array}{c}\text { Number of } \\
\text { researches }\end{array}$ & Percentage \\
\hline Intentional way & 22 & $36.07 \%$ \\
\hline Random way & 31 & $50.82 \%$ \\
\hline $\begin{array}{c}\text { Research did not use } \\
\text { samples }\end{array}$ & 8 & $13.11 \%$ \\
\hline Total & 61 & $100.00 \%$ \\
\hline
\end{tabular}

Figure (4)

Selection methods of samples

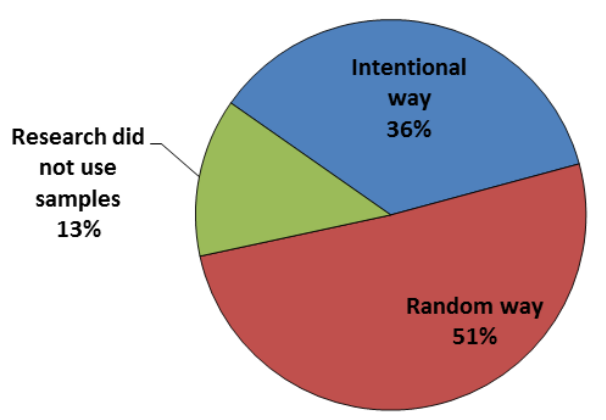

Table (4) and figure (4) showed that the number of research which used the samples selected in intentional way reached 22 by $36.07 \%$ of the total number of under study Researches, and showed that the number of Research which used the samples selected in random way reached 31 by $50.82 \%$ of the total number of under study researches, as there are number 8 research did not used the samples in procedures, that represented in analytical studies and descriptive studies that use of the research community fully.

El-Barrawi, Ehab Hamed (2010) explain this where it refers to the cause of the different ways Sampling selection, due to depend on the type of study and the nature of society, which will represent the sample as well as the nature of the data to be collected from the sample (3: 29), the researchers believe that the prevalence of using random way to 
sampling selection, which exceeded the barrier of $50 \%$ may be due to the fact that the way characterized by the possibility of generalize the results and this is one of the most important goals researchers and scientific research and of exploiting research results optimization through the availability of the possibility of circulation so as to take advantage of them more widespread.

Table (5)

Number of people sample

\begin{tabular}{|c|c|c|}
\hline "N" people sample & $\begin{array}{c}\text { Number of } \\
\text { Researches }\end{array}$ & Percentage \\
\hline Less than 20people & 0 & $0.00 \%$ \\
\hline $20-50$ people & 18 & $29.51 \%$ \\
\hline $51-100$ people & 10 & $16.39 \%$ \\
\hline $101-150$ people & 7 & $11.48 \%$ \\
\hline $151-200$ people & 7 & $11.48 \%$ \\
\hline $201-250$ people & 3 & $4.92 \%$ \\
\hline $251-300$ people & 1 & $1.64 \%$ \\
\hline $301-350$ people & 3 & $4.92 \%$ \\
\hline $351-400$ people & 0 & $0.00 \%$ \\
\hline $401-450$ people & 3 & $4.92 \%$ \\
\hline $451-500$ people & 1 & $1.64 \%$ \\
\hline More than500people & 0 & $0.00 \%$ \\
\hline $\begin{array}{c}\text { Research did not } \\
\text { use samples }\end{array}$ & 8 & $13.11 \%$ \\
\hline Total & 61 & $100.00 \%$ \\
\hline
\end{tabular}

Figure (5) Number of people sample

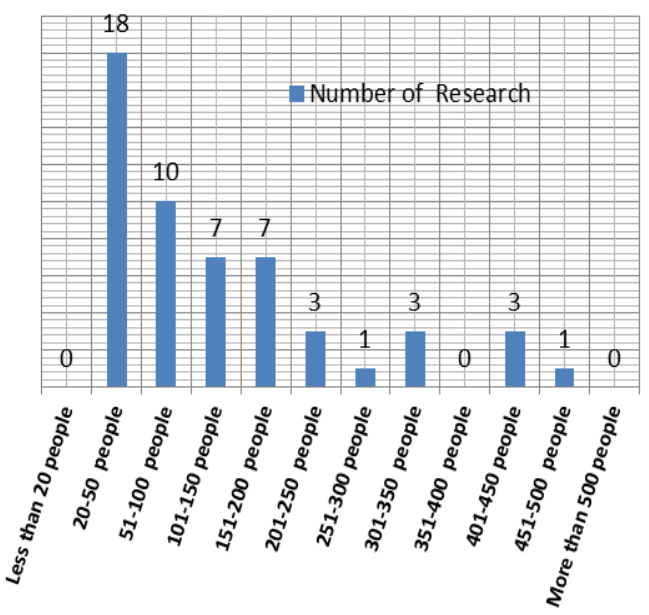

Table (5) showed that the number of people samples ranged between 20 - 500 people that is, all samples under study researches ranged their numbers between 20 - 500 people, and was divided the number of people samples into categories numerical as shown at figure (5), was numerically lower category actually used from 20-50 people and the number of research, which fell into the numbers of samples within this category 18 by $29.51 \%$, while the category that most numerically and actually used 451-500 people and the number of research, which fell into the numbers of samples within this category only one, as there are number 8 research did not used the samples in procedures, that represented in analytical studies and descriptive studies that use of the research community fully.

figure (5) showed that the category widespread and most commonly used in under study researches is a category of 20 50 people and the number of research which fell into the numbers of samples within this category 18 by $29.51 \%$, while category numerical least prevalent among under study Researches is the category of 251-300 people and category of 451-500 people, where the share of each one search only by $1.64 \%$ for each of them, as it turns out that there are categories do not used within the under study researches and represented in a category of less than 20 people and category of more than 500 people and category of 351-400 people.

The researchers believe that it may be due to the desire of researchers in addressing sports shows which using small numbers of people, which fall under the categories numerical 20250 people, for ease of handling in terms of research procedures, especially in experimental research while the researchers did not pay attention to addressing sports shows which using large numbers of people 
and, which fall under the categories numerical more than 250 people, it is shown in the relative variation of the numerical representation categories less than 250 people, which represents approximately $75 \%$ of the total under study Researches, while the numerical categories more than 250 people representing $25 \%$ of the under study researches.

Table (6) sex of people sample

\begin{tabular}{|c|c|c|}
\hline Sex of people sample & $\begin{array}{c}\text { Number of } \\
\text { Researches }\end{array}$ & Percentage \\
\hline Male & 37 & $60.66 \%$ \\
\hline Female & 10 & $16.39 \%$ \\
\hline $\begin{array}{c}\text { Male andFemale } \\
\text { Research did not use } \\
\text { samples }\end{array}$ & 6 & $9.84 \%$ \\
\hline Total & 61 & $13.11 \%$ \\
\hline
\end{tabular}

Figure (6) sex of people sample

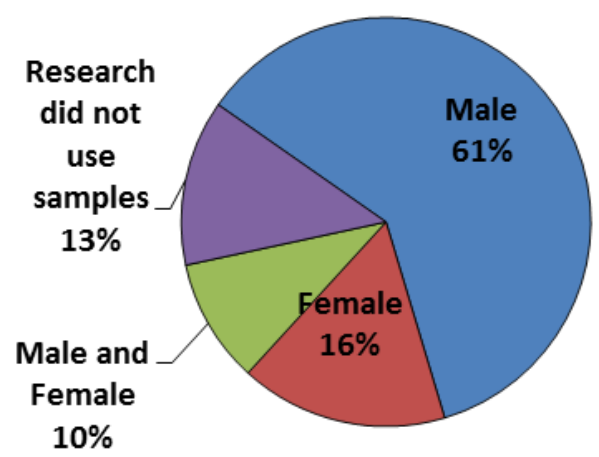

Table (6) and figure (6) showed that males got the largest share of under study researches, as the number of research which used sampled in males 37 by $60.66 \%$ of the under study researches, while we find that the research which used sampled in females has reached 10 by $16.39 \%$, as we find that the research which included samples in (male and female combined) reached 6 by $9.84 \%$, as there are number 8 research did not used the samples in procedures, that represented in analytical studies and descriptive studies, have either dealt with all members of the community or using video tapes or paper documents or CDs, The researchers believe that the big difference between the relative values to undergo males, females or both samples for under study researches may be due to the characteristics of our community eastern and Islamic and which imparts dye religious culture of members of this community, this reflected at reluctance females for physical activity in general and sports shows particularly what might content of the technical reviews and dances requires performance in front of an audience of both sexes, that is consistent with the results of the global study carried out by Hardman, K. and Marshall, J, (2002), which aimed to determine the reality of physical education programs in many countries of the world, and pointed out the most important results to be the Middle East and some Muslim countries, including Egypt, characterized reluctance large proportion of females for physical activity due - according to the results of the study - to religious factors (beliefs - and cultures) and the nature of socialization for these countries saturated with the religious character. (7), Of the above, researchers believe that females reluctance for sporting activities, that would be an obstacle may face researchers when choosing the female samples to be subjected to scientific research which may explain low number of under study researches which dealt with female samples, which amounted to 10 research only, and the cultures and religious beliefs and socialization may be a barrier between researchers and joint sampling of both sexes, which may also explain the low number of research on joint samples of both sexes. 
Table (7)

Ages of people sample

\begin{tabular}{|c|c|c|}
\hline Ages of people sample & $\begin{array}{c}\text { Number of } \\
\text { Researches }\end{array}$ & Percentage \\
\hline $\begin{array}{c}\text { Preschool } \\
\text { "les than 6 years old" }\end{array}$ & 0 & $0.00 \%$ \\
\hline $\begin{array}{c}\text { Primary school level } \\
\text { "6-12 years old" }\end{array}$ & 7 & $11.48 \%$ \\
\hline $\begin{array}{c}\text { Prep school level } \\
\text { "13-15 years old" }\end{array}$ & 14 & $22.95 \%$ \\
\hline $\begin{array}{c}\text { Secondary level } \\
\text { "16-18 years old" }\end{array}$ & 2 & $3.28 \%$ \\
\hline $\begin{array}{c}\text { Undergraduate level } \\
\text { "19-22 years old" }\end{array}$ & 30 & $49.18 \%$ \\
\hline $\begin{array}{c}\text { Post-university } \\
\text { "more than 22 years old" }\end{array}$ & 0 & $\mathbf{0 . 0 0 \%}$ \\
\hline $\begin{array}{c}\text { Non-human samples } \\
\text { Total }\end{array}$ & 8 & $13.11 \%$ \\
\hline 61 & $100.00 \%$ \\
\hline
\end{tabular}

Figure (7)

Ages of people sample

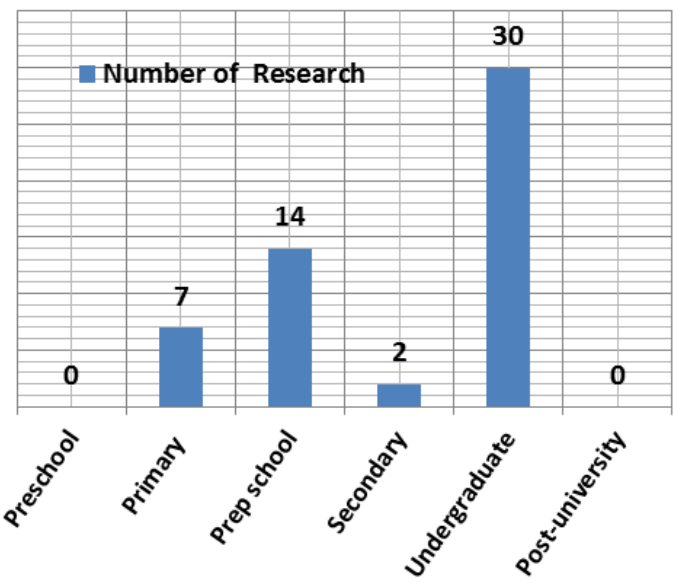

Table (7) showed that the age group which accounted for the largest share of the attention of researchers is Undergraduate "19 - 22 years", the number of research which used samples of this stage has reached 30 by $49.18 \%$ of the total number of under study researches, while we find that phase secondary "16 - 18 years" is the stage at least attention and representative and that the number of 2 by $3.28 \%$, and there is number 8 research did not use the human samples and was used sampled of the media or the recorders, as it turns out the researcher that the pre-school and post-university have not been fortunate interesting researchers, did not mention any researcher to address these phases at the under study researches, Figure (7) showed that there are differences in the representation of ages in under study researches, we find that the Undergraduate " 19-22 years" got the largest share of under study researches, followed by prep school "13-15 years" and then the primary school "6-12 years", and finally secondary "16-18 years". The researchers believe that poor representation in the secondary in the under study researches may be due to the characteristics upbringing study pursued by the Egyptian family, Where intensifying interest in their sons - at this stage - for collecting as many of the scores, This is reflected on the reluctance of students in this stage for the exercise of activities in all its forms and in particular sports activity, and what they sports shows that require more time was one of the most sporting activities negligence and reluctance, in under study researches did not address any research to study sports shows on pre-school stage "less than 6 years", and post-university "more than 22 years" and the elderly, the researchers did not find any scientific reason and logic be inferred by the possibility of interpreting the lack of attention obvious these two phases, but on the contrary, it was one of the most important points weaknesses in the researches which related to sports shows because of the importance of sports shows in preschool as a builders developmental activity, in the post-university and the elderly as a recreational activity. 
Table (8)

Geographic sampling

\begin{tabular}{|c|c|c|}
\hline Geographic sampling & 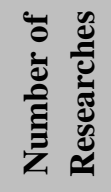 & 总 \\
\hline $\begin{array}{l}\text { Greater Cairo province } \\
\text { "Cairo-Giza-Qaliobia" }\end{array}$ & 10 & $16.39 \%$ \\
\hline $\begin{array}{c}\text { Alexandria province } \\
\text { "Alexandria-AlBeheira- } \\
\text { Matrouh" } \\
\end{array}$ & 16 & $26.23 \%$ \\
\hline $\begin{array}{c}\text { Delta province } \\
\text { "Al Dakahlia-Kafr Sheikh-Al } \\
\text { Gharbia-Al Monofeya- } \\
\text { Damietta" } \\
\end{array}$ & 16 & $26.23 \%$ \\
\hline $\begin{array}{c}\text { Suez Canal province } \\
\text { "Port Said-Ismailia-Suez-El } \\
\text { Sharkeya-Red Sea-North } \\
\text { Sinai-SouthSinai" }\end{array}$ & 4 & $6.56 \%$ \\
\hline $\begin{array}{c}\text { UpperEgypt province } \\
\text { "BeniSuef-Fayoum-Minya- } \\
\text { Assiut-El Wadi El Gadid- } \\
\text { Sohag-Qena-Luxor-Aswan" } \\
\end{array}$ & 2 & $3.28 \%$ \\
\hline Samples fromoutsideEgypt & 5 & $8.20 \%$ \\
\hline Non-human samples & 8 & $13.11 \%$ \\
\hline Total & 61 & $100.00 \%$ \\
\hline
\end{tabular}

Figure (8)

Geographic sampling

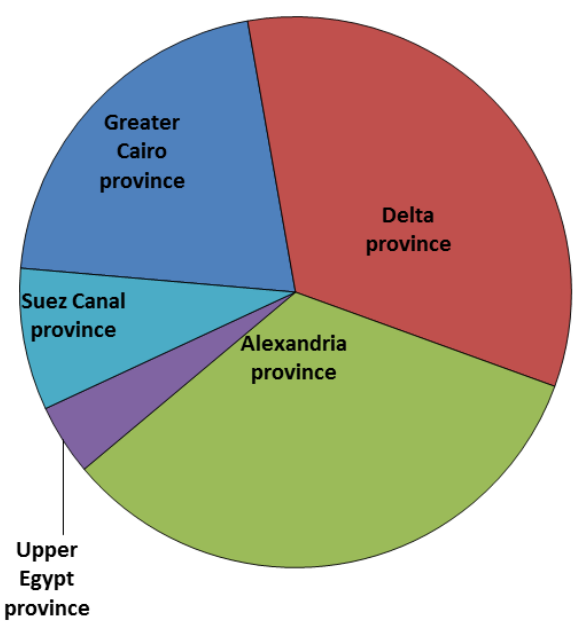

Table (8) showed that there is variation in the geographical distribution in the under study researches, where resorted researchers to divide Egypt geographically - in this study to the provinces according to the latest division of geographical issued by the Egypt State Information Service (14), in which divided Egypt geographically to five provinces as shown in Table (8), and it became clear that Upper Egypt province was the least attention of researchers, the researches numbers which conducted on samples from the Upper Egypt province reached 2 by $3.28 \%$ of the total number of under study researches, while Alexandria province and Delta province were had been captured the attention of researchers. The researches numbers which conducted on samples from Alexandria province 16 searches by $26.23 \%$, and Delta province 16 searches by $26.23 \%$ of the total number of under study researches, also found that there are 5 researches conducted on samples from outside Egypt but published in Egyptian scientific journals specialized, also show that 8 researches did not use the human samples. Despite the fact that the distribution of scientific research institutions and of universities and institutes on the regions of the Republic distributor in moderate way commensurate with almost governorates every province but there is variation evident in the geographical distribution of the under study researches, the researchers believe it may be due to the population census of the provinces As is clear from figure (8) that the Delta province, Alexandria province and Greater Cairo province had been captured the attention of researchers, where represented a combined exceed $75 \%$ of human samples used in under study researches, commensurate with the population of those regions which exceed combined $75 \%$ of Egypt's population, either Suez Canal province and Upper Egypt province are least attention, where represented together less than $25 \%$ of human samples used in under 
study researches and also commensurate with the population of those regions which nearly $25 \%$ of Egypt's population.

Table (9)

Tools in sports shows

\begin{tabular}{|c|c|c|}
\hline Geographic sampling & $\begin{array}{c}\text { Number of } \\
\text { Researches }\end{array}$ & Percentage \\
\hline $\begin{array}{c}\text { Sports shows with } \\
\text { tools }\end{array}$ & 35 & $57.38 \%$ \\
\hline $\begin{array}{c}\text { Sports shows without } \\
\text { tools }\end{array}$ & 18 & $29.51 \%$ \\
\hline $\begin{array}{c}\text { Research did not } \\
\text { address the technical } \\
\text { side of sports shows }\end{array}$ & 8 & $13.11 \%$ \\
\hline Total & 61 & $100.00 \%$ \\
\hline
\end{tabular}

Figure (9)

Tools in sports shows

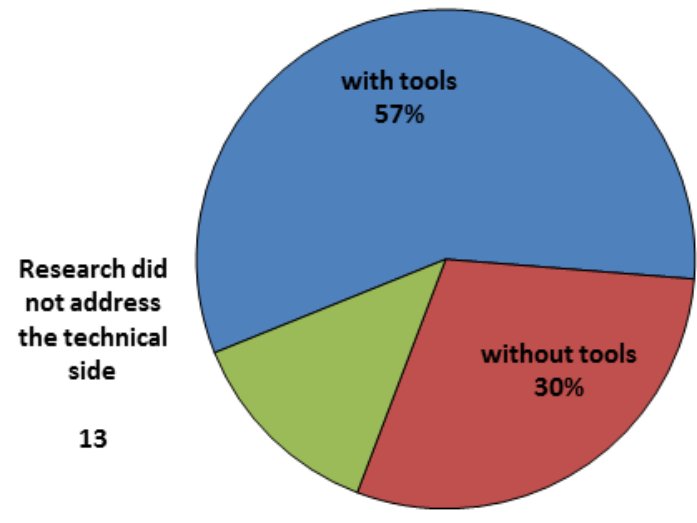

Table (9) and figure (9) showed that sports shows with tools was ranked first in terms of the attention of researchers, and the number of researches which addressed the sports shows with tools reached 35 by $57.38 \%$, while the sports shows without tools was ranked second in terms of the attention of researchers, and the number of researches which addressed the sports shows without tools reached 18 by $29.51 \%$, it turns out that there are 8 research did not address the technical side of sports shows, but addressed the sports shows in general and closer to the theories and management systems.

The researchers believe that the attention of researchers to address the tools in sports shows may be due to the importance of their use, and the consequent positive results when employed properly, as the multiplicity and diversity of those tools led to acquisition of a larger share of the attention of researchers, Faraj, Inayat Mohammed. (1995).refers to that the employment of tools in the sports show properly, helps to achieve the excitement and thrill and increases the motivation, also pave the way for training on various skills, as well as it Increase the beauty of the exercise in sports shows. (4: 201) 
Table (10)

Qualitative and Numerical analysis of variables that were addressed in the research under study

\begin{tabular}{|c|c|c|c|c|c|}
\hline \multirow{2}{*}{\multicolumn{2}{|c|}{ The field and its variables }} & \multicolumn{2}{|c|}{$\begin{array}{l}\text { addressing the } \\
\text { variables }\end{array}$} & \multirow{2}{*}{$\stackrel{\text { ڤี }}{0}$} & \multirow{2}{*}{ 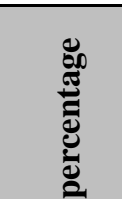 } \\
\hline & & $\mathbf{N}$ & Percentage of its & & \\
\hline \multirow{18}{*}{$\begin{array}{l}\text { The field of coordination, } \\
\text { movement, physical abilities }\end{array}$} & Speed & 9 & $6.72 \%$ & \multirow{18}{*}{134} & \multirow{18}{*}{$59.29 \%$} \\
\hline & Flexibility & 12 & $8.96 \%$ & & \\
\hline & Agility & 14 & $10.45 \%$ & & \\
\hline & Muscular strength & 11 & $8.21 \%$ & & \\
\hline & Accuracy & 6 & $4.48 \%$ & & \\
\hline & Ability & 11 & $8.21 \%$ & & \\
\hline & Kinesthetic perception & 5 & $3.73 \%$ & & \\
\hline & Rhythmic ability & 5 & $3.73 \%$ & & \\
\hline & Balance & 11 & $8.21 \%$ & & \\
\hline & Compatibility & 10 & $7.46 \%$ & & \\
\hline & Endurance & 9 & $6.72 \%$ & & \\
\hline & $\begin{array}{c}\text { The ability to } \\
\text { differentiate position }\end{array}$ & 5 & $3.73 \%$ & & \\
\hline & $\begin{array}{c}\text { The ability to } \\
\text { movement combining }\end{array}$ & 6 & $4.48 \%$ & & \\
\hline & $\begin{array}{c}\text { The ability to exert the } \\
\text { suitable effort }\end{array}$ & 5 & $3.73 \%$ & & \\
\hline & $\begin{array}{c}\text { The ability to quick } \\
\text { reaction }\end{array}$ & 5 & $3.73 \%$ & & \\
\hline & $\begin{array}{c}\text { The ability to space } \\
\text { orientation }\end{array}$ & 5 & $3.73 \%$ & & \\
\hline & $\begin{array}{l}\text { Adapt to changing } \\
\text { conditions }\end{array}$ & 5 & $3.73 \%$ & & \\
\hline & Total this field & 134 & $100 \%$ & & \\
\hline \multirow{6}{*}{$\begin{array}{c}\text { The field of psychosocial, mental } \\
\text { abilities }\end{array}$} & Intelligence & 1 & $2.86 \%$ & \multirow{6}{*}{35} & \multirow{6}{*}{$15.49 \%$} \\
\hline & Creativity & 2 & $5.71 \%$ & & \\
\hline & Movement satisfaction & 4 & $11.43 \%$ & & \\
\hline & $\begin{array}{l}\text { Esteem and Self- } \\
\text { Concept }\end{array}$ & 4 & $11.43 \%$ & & \\
\hline & $\begin{array}{c}\text { Temperamental } \\
\text { patterns }\end{array}$ & 3 & $8.57 \%$ & & \\
\hline & Social construction & 1 & $2.86 \%$ & & \\
\hline
\end{tabular}




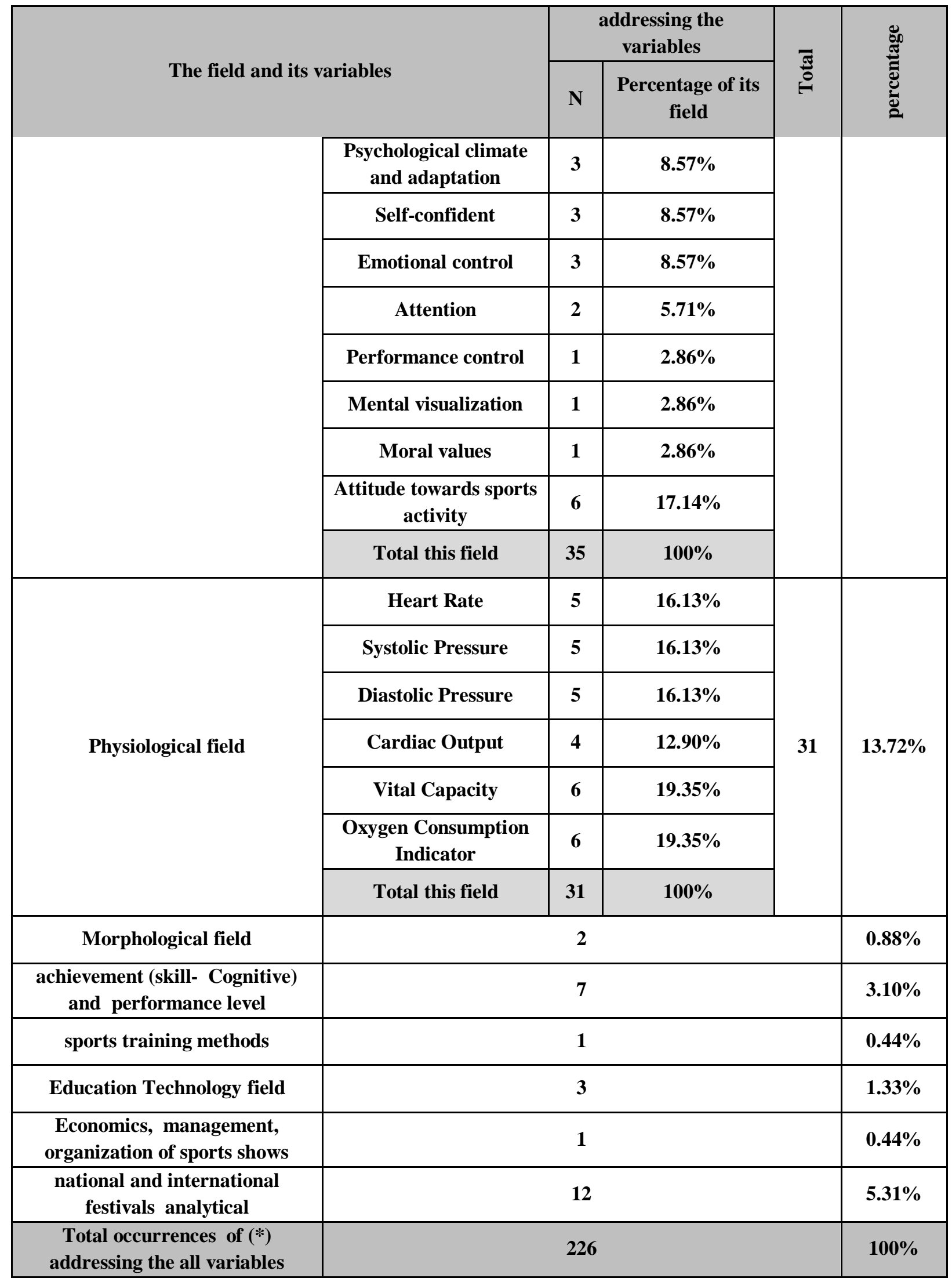

(*) in table (10) we find that some of the research addressed more than a variable associated with sports shows, maybe we find any one of under study researches addressing 
one variable from Physiological field, and one variable from Morphological field, and one variable from The field of psychosocial, mental abilities, all this variables in the same research, Therefore the Total occurrences of addressing the all variables in table (10) not means total of researches (61 researches), but it means total of vocabulary of variables which are addressed in under study researches, This is because may be more than variables have been addressed in the same research.

Figure (10)

Qualitative and Numerical analysis of all variables

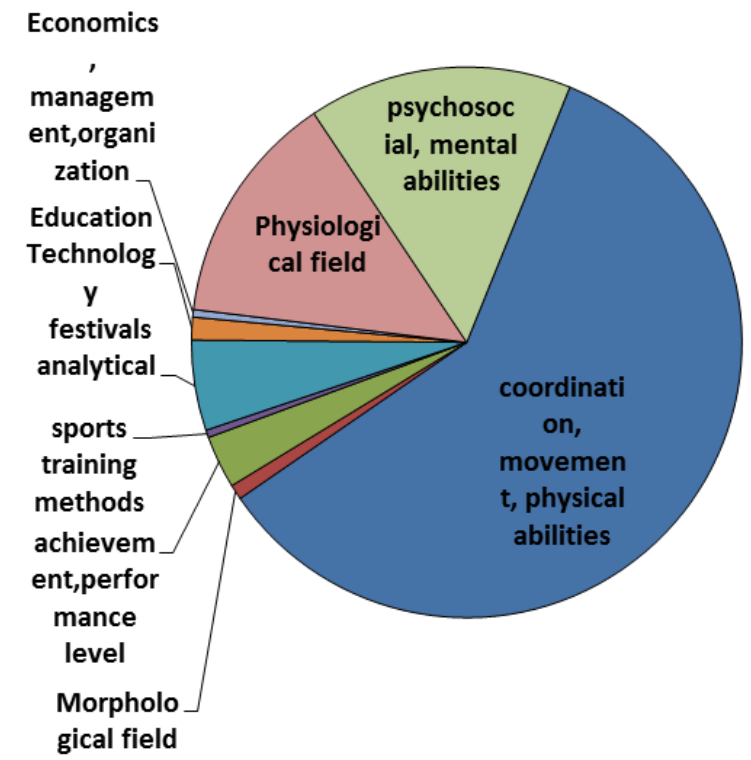

Figure (11)

Qualitative and Numerical analysis of variables of the field of coordination, movement, physical abilities

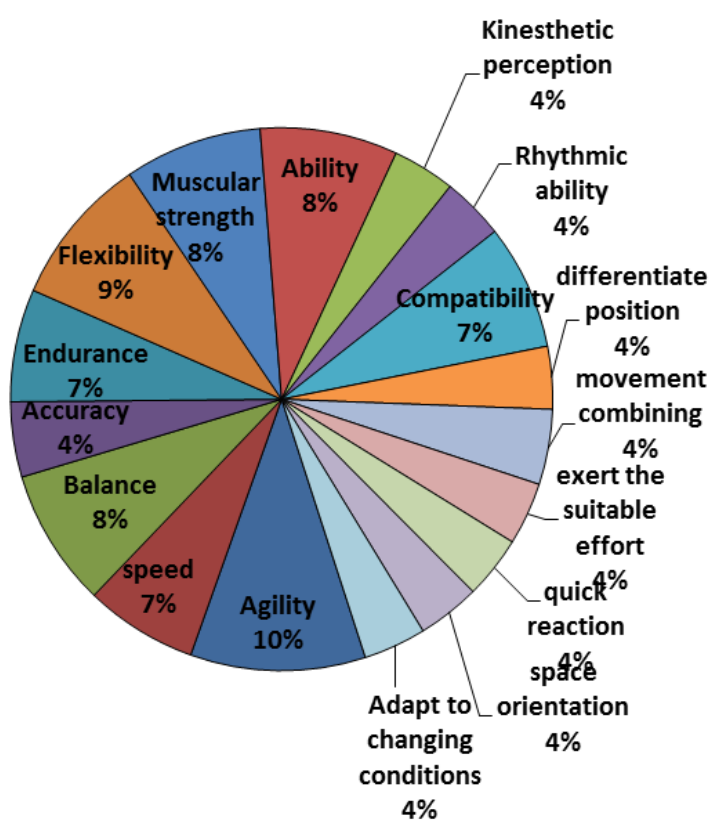


Figure (13)

Qualitative and Numerical analysis of variables of Physiological field

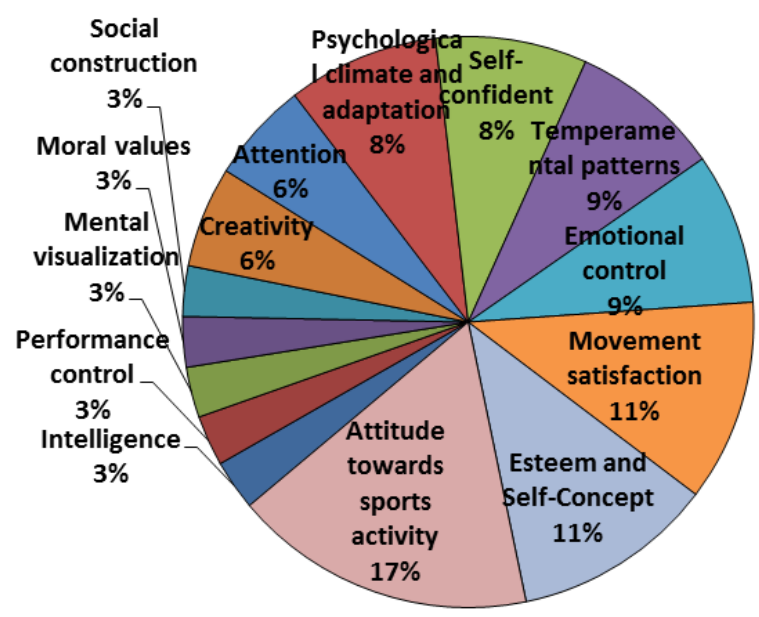

Figure (12)

Qualitative and Numerical analysis of variables of the field of psychosocial, mental abilities

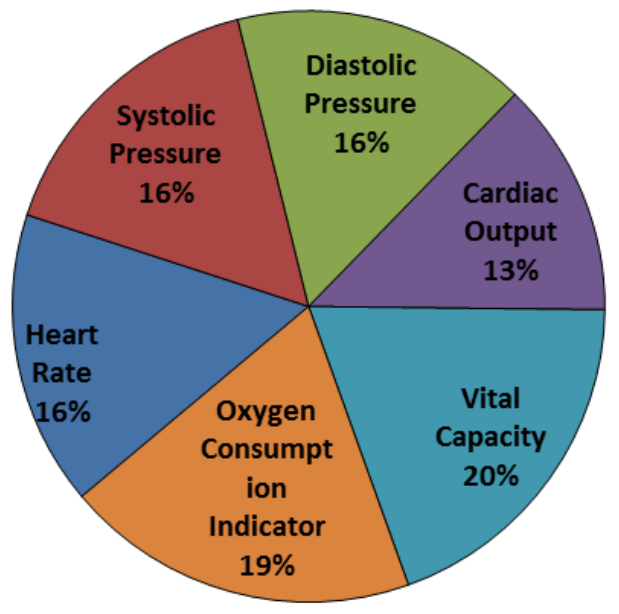

Table (10) and figure (10) showed that there is variation in the results of the qualitative and numerical analysis of variables that associated with the sports shows and were addressed by the under study researches, in terms of the extent of the attention of researchers, It turns out that variables of field of coordination, movement, physical abilities has ranked first in terms of the attention of researchers that were addressed 134 times by $59.29 \%$ of the total occurrences of addressing the all variables in the under study researches, followed by the variables of field of psychosocial, mental abilities in second place where addressed 35 times by $15.49 \%$, while come variables of physiological field in third that were addressed 31 times by $13.72 \%$, while we find in ranked last both of the variables of sports training methods and variables of Economics, management, organization of sports shows, where they were addressed Once for both of them by $0.44 \%$ of the total occurrences of addressing the all variables in the under study researches, As it turns out that there are many variables and fields that associated with the sports shows, but it has not been addressed by any researcher in the under study 
researches, such as the teaching methods of sports shows, recreation in sports shows, history of sports shows, biomechanics and kinetic analyzes.

Table (10) and figure (11) showed qualitative numerical analysis of variables field of coordination, movement, physical abilities were addressed by researchers in the under study researches, we find that the variables field of coordination, movement, physical abilities reached within under study researches 17 variables and there was a variation in the attention of researchers to address these variables, agility ranked first reached 14 times of $10.45 \%$ of the total occurrences of The field of coordination, movement, physical abilities, while we find that ranked last went to each of the Kinesthetic perception, Rhythmic ability, The ability to differentiate position, The ability to exert the suitable effort, The ability to quick reaction, The ability to space orientation, and Adapt to changing conditions where they have been had addressed 5 times for each of them by $3.73 \%$ of the total occurrences of variables field of coordination, movement, physical abilities.

Table (10) and figure (12) showed qualitative and numerical analysis of variables field of psychosocial, mental abilities were addressed by researchers in the under study researches, we find that the variables field of psychosocial, mental abilities reached within under study researches 14 variables and there was in the attention of researchers to address these variables, attitude towards sports activityranked first with 6time by $17.14 \%$ of the total occurrences of The field of psychosocial, mental abilities, while we find that ranked last went to each of the intelligence, social construction, performance control, mental visualization and moral values were they have been hadaddressed only once for each of them by $2.86 \%$ of the total occurrences of variables field of psychosocial, mental abilities.

Table (10) and figure (13) showed qualitative and numerical analysis of variables of Physiological field were addressed by researchers in the under study researches, we find that the variables of Physiological fieldreached within under study researches6 variables and there was in the attention of researchers to address these variables, both of Vital Capacity and Oxygen Consumption Indicator ranked first with 6 time for each of them by $19.35 \%$ of the total occurrences of variables of Physiological field, while we find that ranked last was Cardiac Outputwith 4 times by $12.90 \%$ of the total occurrences of variables of Physiological field.

\section{Conclusions}

1. The number of scientific research (producing scientific - Master - PhD) in sports shows that have been published or accepted in the period from 1980 2010 (61) searches, It is divided in terms of type to 14 Masters, 4 messages Ph.D. 0.43 Search produce a scientific publication in Egyptian universities

2. There are the extrusive positive correlation between the number of researches and between the over time, any that whenever progress us time whenever numbers of research increased in the field of sports shows where recorded the largest number of research that have been published, and thesis that have been accepted in period from the 2006 to 2010 and amounted to 20 research and thesis.

3. Experimental method is the most widely used research methods while not using the historical method at all. 
4. The random way in the selection of research samples ranked first in terms of sampling methods.

5. The number of people sample that underwent researches has ranged between 20 - 500 people within a one search that is, it did not exceed any sample search for 500 people and it did not less any sample search for 20 people, as that most widely used Category is that ranged between 20 50 people.

6. Male ranked first, while in ranked last cross-gender samples, in terms of sex of people sample in under study researches.

7. The age group which accounted for the largest share of the attention of researchers is Undergraduate "19 - 22 years", this Category where underwent to nearly $50 \%$ of the under study researches, while there were not any research samples of pre-school (less than 6 years) and post-university and older (greater than 22 years).

8. Both of Alexandria province and Delta province ranked first and they were most attention by researchers, while that UpperEgypt province is least attention by researchers .

9. The researchers focused on the addressed of sports shows with tools while sports shows without tools were least attention by researchers.

10. there is no relative balance between the variables associated with the sports shows In terms of the extent of attention of researchers, has found that there are three fields have accounted attention by researchers and they were in the first ranks, they were the field of coordination, movement, physical abilities -the field of psychosocial, mental abilities - Physiological field, while found to be other fields despite its importance, but they were the least ranks, also found that there are fields associated with the sports shows, but it was not addressed in any research from under study researches, such as the teaching methods of sports shows, recreation in sports shows, history of sports shows, biomechanics and kinetic analyzes.

\section{Recommendations}

In light of the results of study, which was reached, the researcher recommends with the following:

1. Those involved in the development of research plans in universities, that takes into account realize relative imbalance between the areas of research associated with sports shows through the inclusion of those fields within the research plan and work to guide and direct and encourage researchers to be addressed in studies and researches.

2. Researchers to Necessity of bring some kind of relative balance in the study of the fields associated with the sports shows, by giving a larger part of their attention to address the fields and the variables that have not yet attained much attention.

3. Researchers to necessity conduct similar studies in other sports fields. 


\section{References}

1. Amin, Hussein Omar and Mohamed, Marwa Fathy. (1992).An analytical study for the theses and dissertations in the field of School sport In the period from 1980 to 1990. Research published in the "vision for the future of school education", Vol1, Helwan university Press, Egypt.

2. Elbahar, Yasmin Hassan and Abdel Halim, Mona Mahmoud. (1991). An analytical study for the theses and dissertations in the field of exercises In the period from 1972 to 1990. Journal of Physical Education and Sports, Faculty of Physical Education for Boys-Helwan University, No.9, January 1991

3. El-Barrawi, Ehab Hamed. (2010). Principles of Applied Statistics in Sports Education. 6 October Press, Mansoura, Egypt

4. Faraj, Inayat Mohammed. (1995).Competitive rhythmic exercises and sports shows. Dar elfikr el araby, Egypt

5. Faraj, Inayat Mohammed and El batal, Faten Mohamed. (2004). Rhythmic exercises and rhythmic gymnastics and sports Shows. Dar elfikr el araby, Egypt

6. Ghoneim, Mohamed Abdel Aziz and Farghali, Majid Mohamed and Ahmed, Abdel Hafiz Ismail. (2001). An analytical study of the scientific research in the field of boxing In the period from 1972to 1990. In: Majeed, Rissan Khuraibet (Editor), Research Encyclopedia of Physical Education In the Arab World. Dar Elmnahej Press, Oman

7. Hardman, K. and Marshall, J. (2002). The World-Wide Survey of Physical Education in Schools, Issues and Strategies for a Sustainable Future. The British Journal of Teaching Physical Education, 32(1): 29-31.

8. Khattab, Attiyat Mohamed and Fekry, Maha and Abdel Wahab, Shahira. (2006). Basics of exercise and rhythmic exercises. Markaz alketab Publishing, Egypt

9. Moneisi, Iman Mohammed Sadiq. (1995). Study to identify the reasons for the disappearance of exercises shows of the second episode of the schools of basic education in Alexandria. Master Thesis, Faculty of Physical Education for Girls, Alexandria University

10. Saber, Fatima Awad and Khafajah, Mervat Ali. (2002). Foundations and principles of scientific research. Alesha' alfaniya Publishing, Alexandria, Egypt

11. Saleh, Saleh Mohammed. (2001). An analytical study for the theses and dissertations in the field of Water Sports In the period from 1972 to 1992 . In: Majeed, Rissan Khuraibet (Editor), Research Encyclopedia of Physical Education in the Arab World. Dar Elmnahej Press, Oman

12. Zahran, Lilly Abdel Aziz. (1997). Scientific and practical bases for technical exercises and exercise. Dar elfikr el araby, Egypt

13. http://www.capmas.gov.eg/reports/high_dgr ee/frm1high_dgree.aspx?parentid=574\&id= 575\&free $=1 \quad(9-12-2012)$

14. http://www.sis.gov.eg/ar/FourStTemplate.as px?Category_ID=16 (10-1-2013) 
